\title{
A material and technical study of Paracas painted ceramics
}

\author{
Dawn Kriss ${ }^{1, *}$, Ellen Howe ${ }^{2}$, Judith Levinson ${ }^{3}$, Adriana Rizzo ${ }^{4}$, \\ Federico Caro ${ }^{4} \&$ Lisa DeLeonardis ${ }^{5}$
}

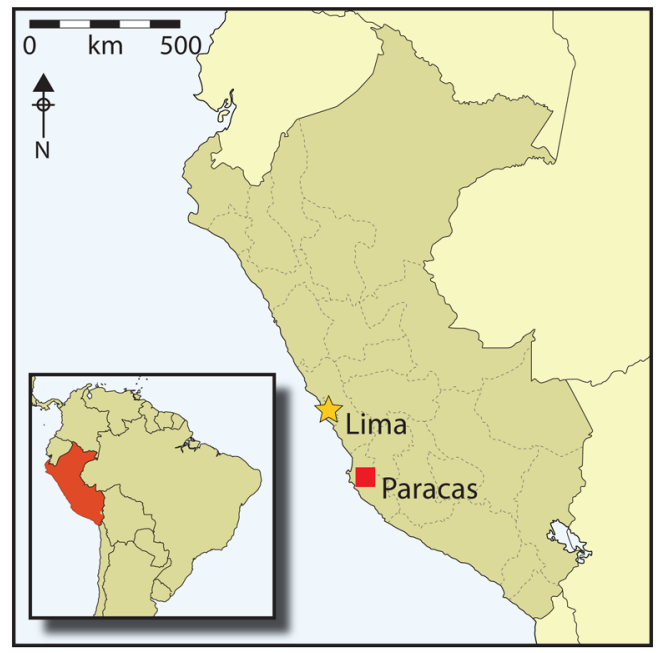

The Paracas culture of Late Formative Period south coastal Peru (c. 900-100 BC) is renowned for its elaborate and colourful ceramics-particularly those decorated using the post-fire painting technique. The materials and the methods used to achieve post-fire painting, however, remain elusive. To investigate the evolution of, and regional variation in, this technology, the authors deploy a range of techniques to analyse a sample of Paracas ceramics curated in museum collections. The results indicate diachronic and regional variations in the paint binders and colourants used by the Paracas potters, which correlate with changes in vessel form and iconography over time.

Keywords: Peru, Paracas, Chavín, Early Horizon, ceramic technology, pigments

\section{Introduction}

The Paracas culture (c. 900-100 BC) of south coastal Peru is widely recognised for its impressive material culture. Vibrantly coloured ceramic effigies and textiles first gained international attention in the 1920s following the extensive excavations of cemeteries by Julio C. Tello and Toribio Mejía on the Paracas Peninsula (Figures 1-2). Tello and his team identified shaft and chamber tombs (cavernas) that contained a distinct form of painted and incised ceramic. Embroidered textiles recovered from another set of Paracas tombs (Necropolis, Arena

1 Brooklyn Museum, Conservation Department, 200 Eastern Parkway, Brooklyn, NY 11217, USA

2 Metropolitan Museum of Art, Sherman Fairchild Center for Objects Conservation, $10005^{\text {th }}$ Avenue, New York, NY 10028, USA

3 American Museum of Natural History, Anthropology Division Objects Conservation Laboratory, Central Park West \& $79^{\text {th }}$ Street, New York, NY 10024, USA

4 Metropolitan Museum of Art, Department of Scientific Research, $10005^{\text {th }}$ Avenue, New York, NY 10028, USA

5 Johns Hopkins University, History of Art, 3400 North Charles Street, Baltimore, MD 21218, USA

* Author for correspondence (Email: dawnkriss@gmail.com) 


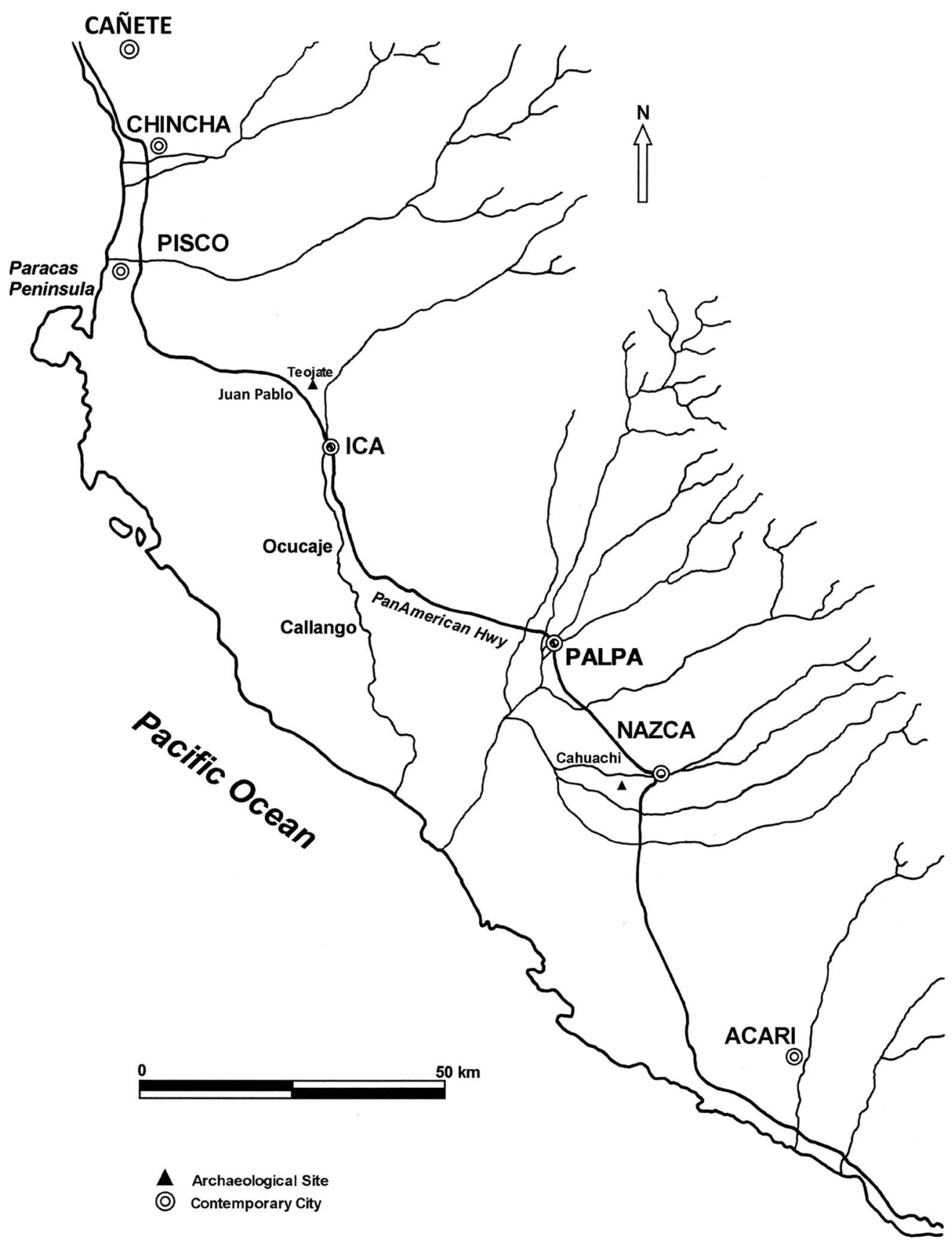

Figure 1. The south coast of Peru (drawing by Lisa DeLeonardis).

Blanca/Cabeza Larga) of later date help to illustrate the development of Paracas cultural practices and artefacts (Tello \& Mejía 1979). 


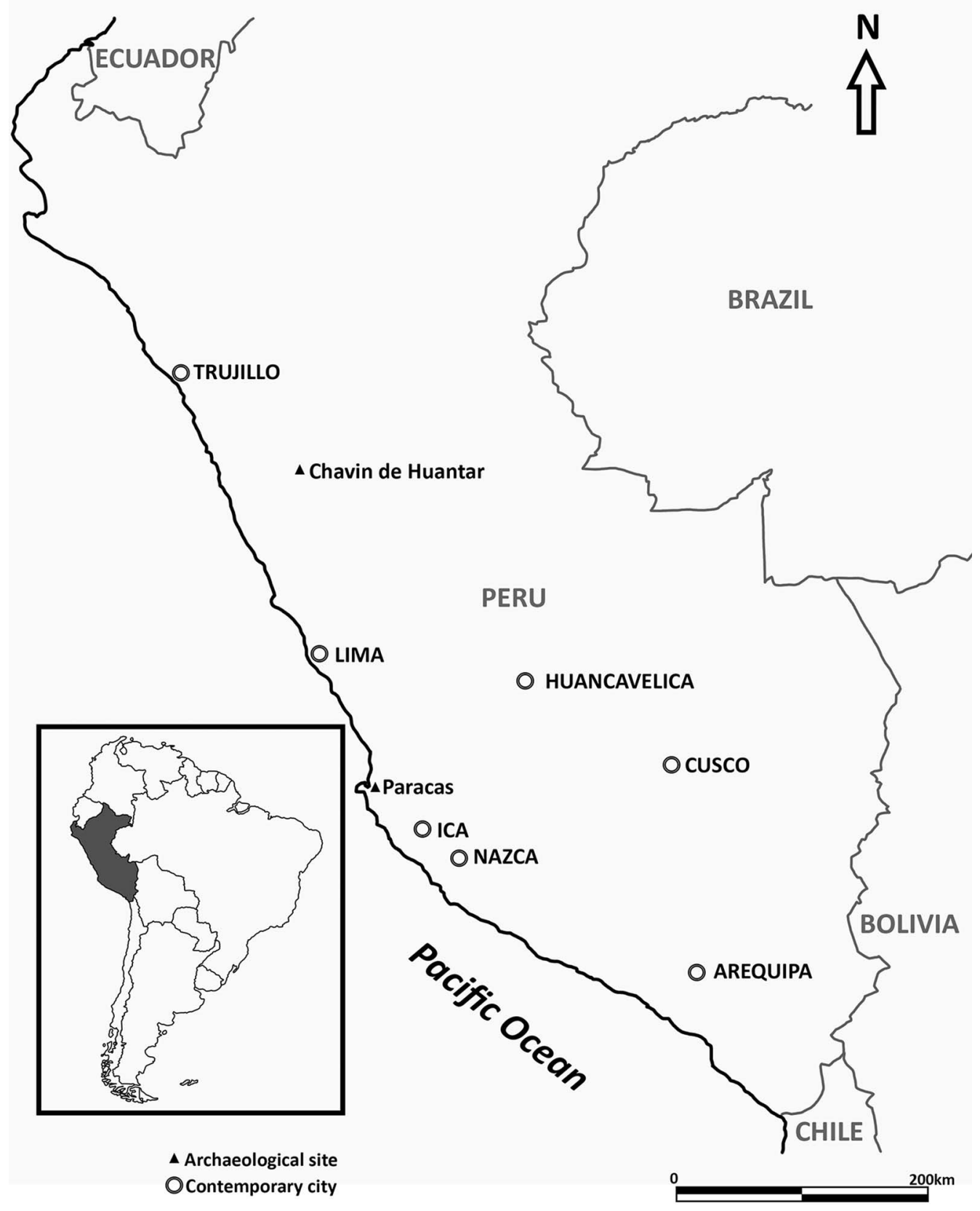

Figure 2. The relationship between the Paracas region and surrounding areas (drawing by Dawn Kriss).

Since that early work, Paracas cultural remains have been found as far north as Mala and as far south as Acarí (Figure 1). Paracas settlement dates to the first millennium BC, known in Andean prehistory as the Early Horizon or Late Formative Period. The Paracas ceramic (C) Antiquity Publications Ltd, 2018 
tradition featured a range of geometric and anthropomorphic designs, frequently utilising a technique known as post-fire painting; this involved incising decoration onto the surfaces of ceramic vessels prior to firing and then applying paints - mixtures of binder and pigmentafter firing. Other decorative practices used in the production of Paracas ceramics include the more common application of slip, a liquefied suspension of clay particles, onto the surface prior to firing, but it is the more distinct and culturally specific method of post-fire painting used by the Paracas potters to achieve polychromy that is the focus of this paper. Despite the cultural significance of the distinct post-fire painting technique for the production of polychrome wares, no large-scale systematic study of the materials and methods involved has been undertaken to date. The present study fills this gap and contributes to an evolving understanding of the ways in which technology inform craft organisation and human agency in the production of material culture (Shimada 1994; Dobres 2000; Costin 2016). It equally informs understanding of the role that raw material exchange may have played in the development of pre-Columbian Andean cultures. These questions are of cross-cultural importance, particularly in the Andes, where, in the absence of writing, ceramic and textile traditions represented the principal form of cultural communication across long distances and multiple generations.

\section{Project description}

The goal of the present study was to investigate ceramic decoration practices and their evolution through the comprehensive analysis of the binders and pigments used in Paracas postfire painting. Collections at the American Museum of Natural History (AMNH) and The Metropolitan Museum of Art (MMA) were accessed in order to conduct a broad survey and scientific study of manufacturing techniques and materials. Paracas ceramics in each collection were examined, documented, photographed and analysed. The AMNH houses several hundred Paracas ceramic objects, the majority of which were recovered by Pablo Soldi (Menzel et al. 1964: i) from the Juan Pablo cemeteries at Teojate in the upper Ica Valley and from the Ocucaje region of the middle Ica Valley (Figures 1-2). A number of Paracas sites are located in the Ocucaje region, but site names were not always specified when the collections entered the museum. Two vessels are said to be from a tomb in Coyungo, in the Nazca Drainage (Lapiner 1976: cat. 145) (Figure 3: left \& right).

The MMA also houses several hundred Paracas ceramic objects, primarily from the Juan Pablo cemeteries at Teojate (Sawyer 1966: 101) (Figures $1 \& 4$ ) and from the Cerro de la Capilla site at Ocucaje (Sawyer 1966: figs 104 \& 129) (Figure 5: left \& Figure 6: left). Some objects are recorded simply as being found in the Ica Valley, or from Ocucaje. One object was recovered from excavations in the region of Chiquerillo in the lower Ica Valley (Sawyer 1966: fig. 100) (Figure 3: centre). Compared to ceramics recovered from other sites, the painted decorations of ceramics from Juan Pablo show greater deterioration, but they are included in this study for comparison with material from other regions where paint is better preserved (see Figure 4).

To test for potential changes in paint technology over time, our sample was selected from ceramics that cover a chronological range. Although the samples have not been dated by absolute methods, they have been sorted according to established seriations. Menzel et al. (1964)

(C) Antiquity Publications Ltd, 2018 
Dawn Kriss et al.
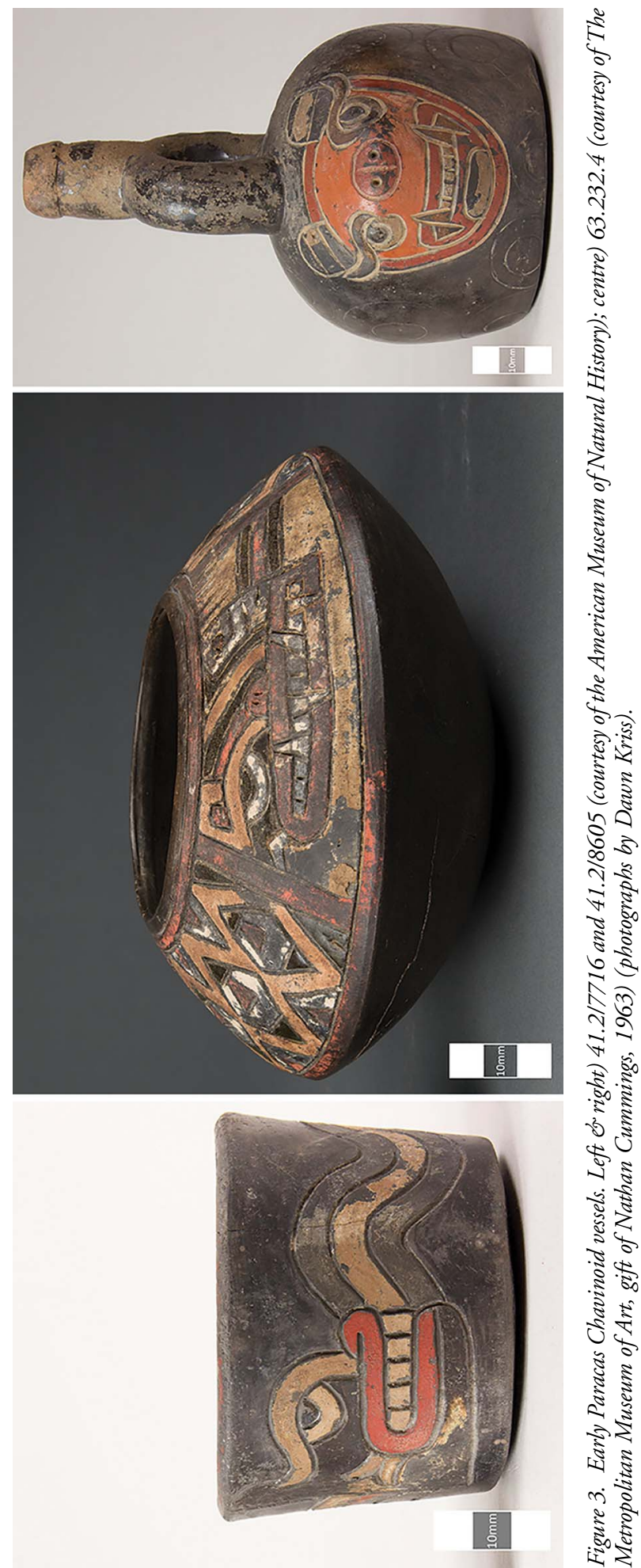

(C) Antiquity Publications Ltd, 2018

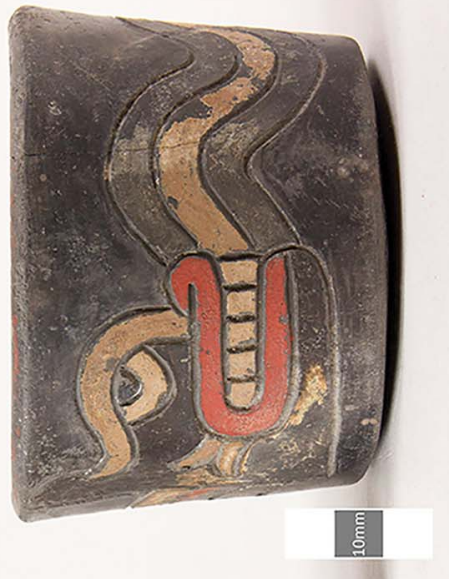

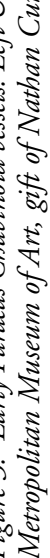




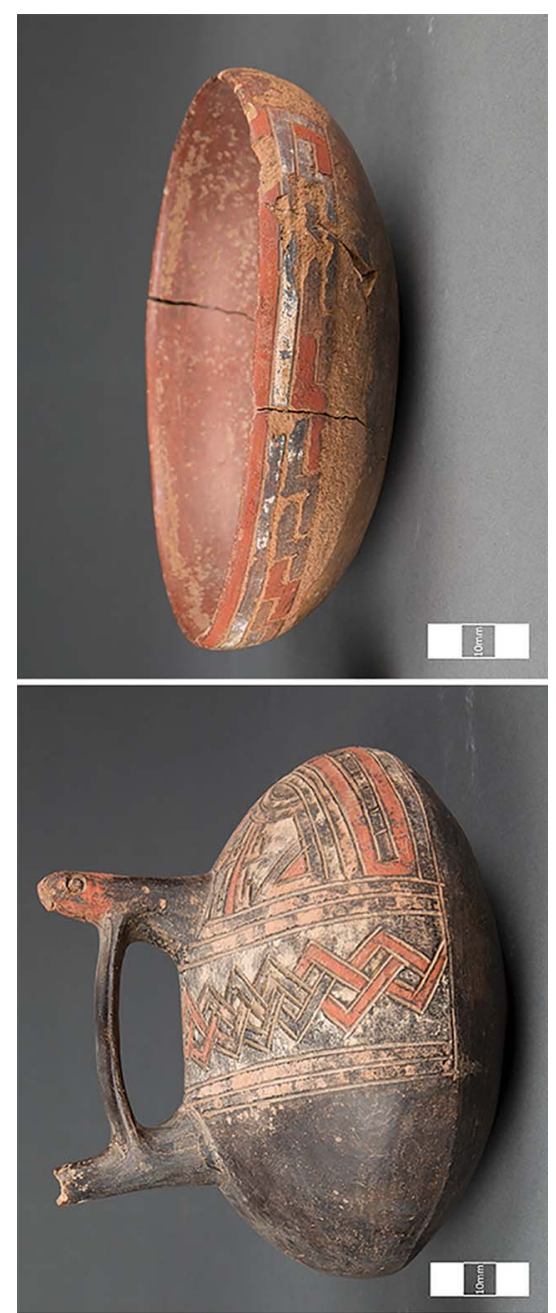

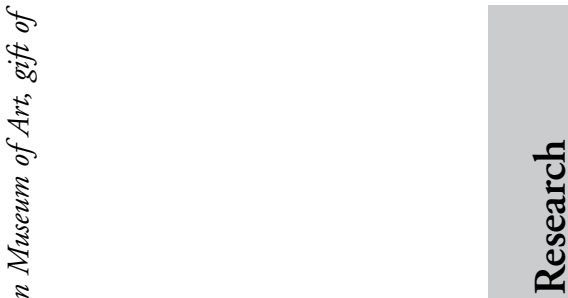

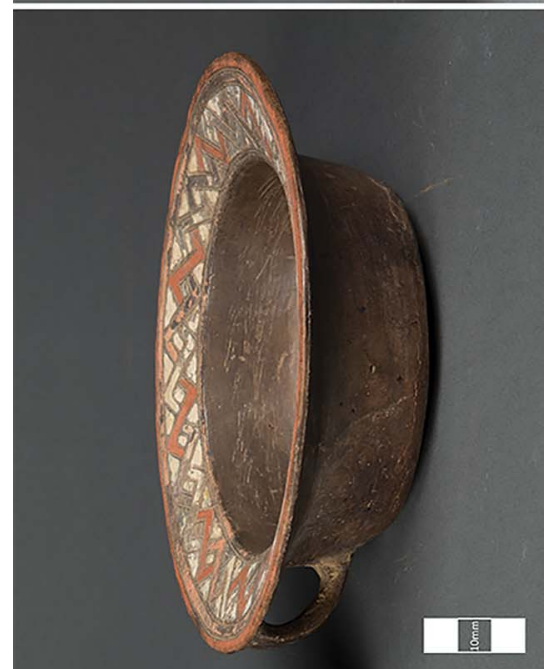

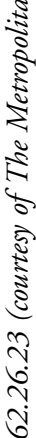

กิ

$\stackrel{\infty}{\stackrel{0}{*}}$

హु

$\underset{1}{ \pm}$

$\stackrel{\sim}{\sim}$

$\forall$

.

8 年

必客

₹

造年

कृ

$\frac{2}{2} 8$

8

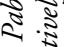

㲾

ฐิ

ปั

उู

ह

$\therefore$ है

곤

ฉ

$\forall i$

วิ

这发

(C) Antiquity Publications Ltd, 2018 
Dawn Kriss et al.

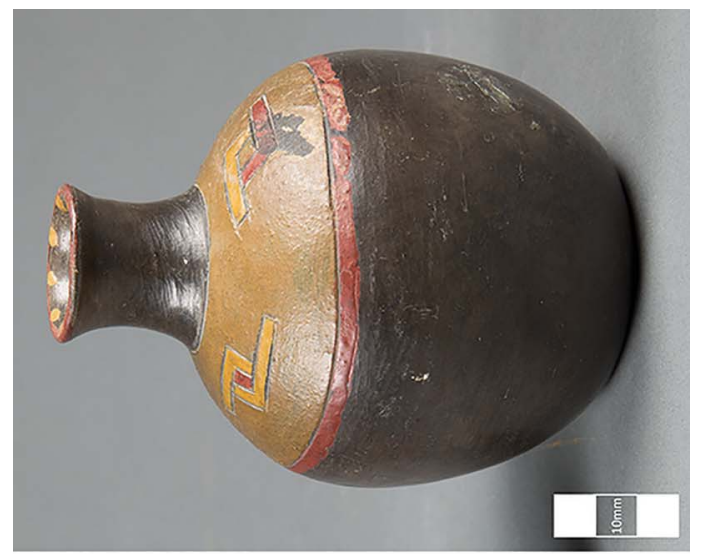

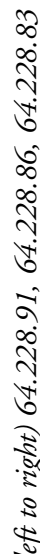
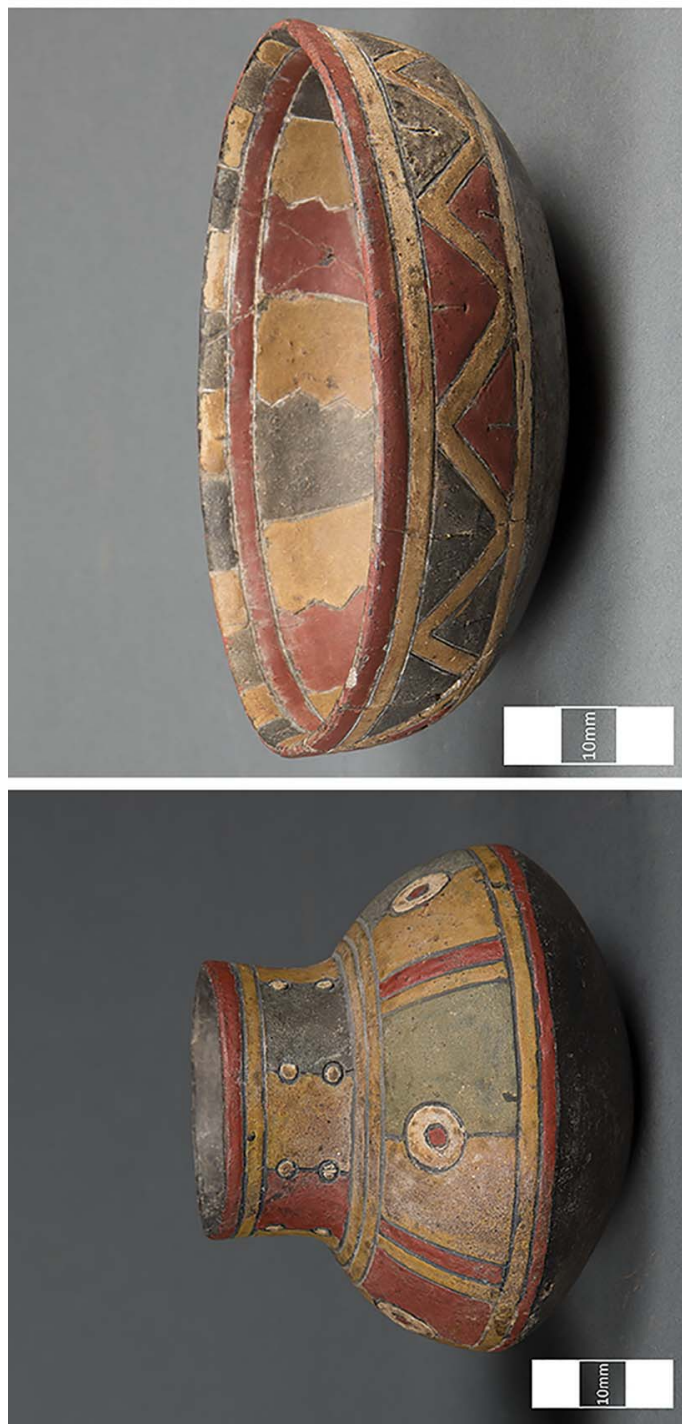

है

亭

హิ

$\sim$

.

₹

है

o

为

से

S

ริ

$\Sigma$

5

8

ह

है

के

है

8

है

ड

8

है ร

है ह

จ

จู के

\&

त है

is

30

(C) Antiquity Publications Ltd, 2018

\section{8}



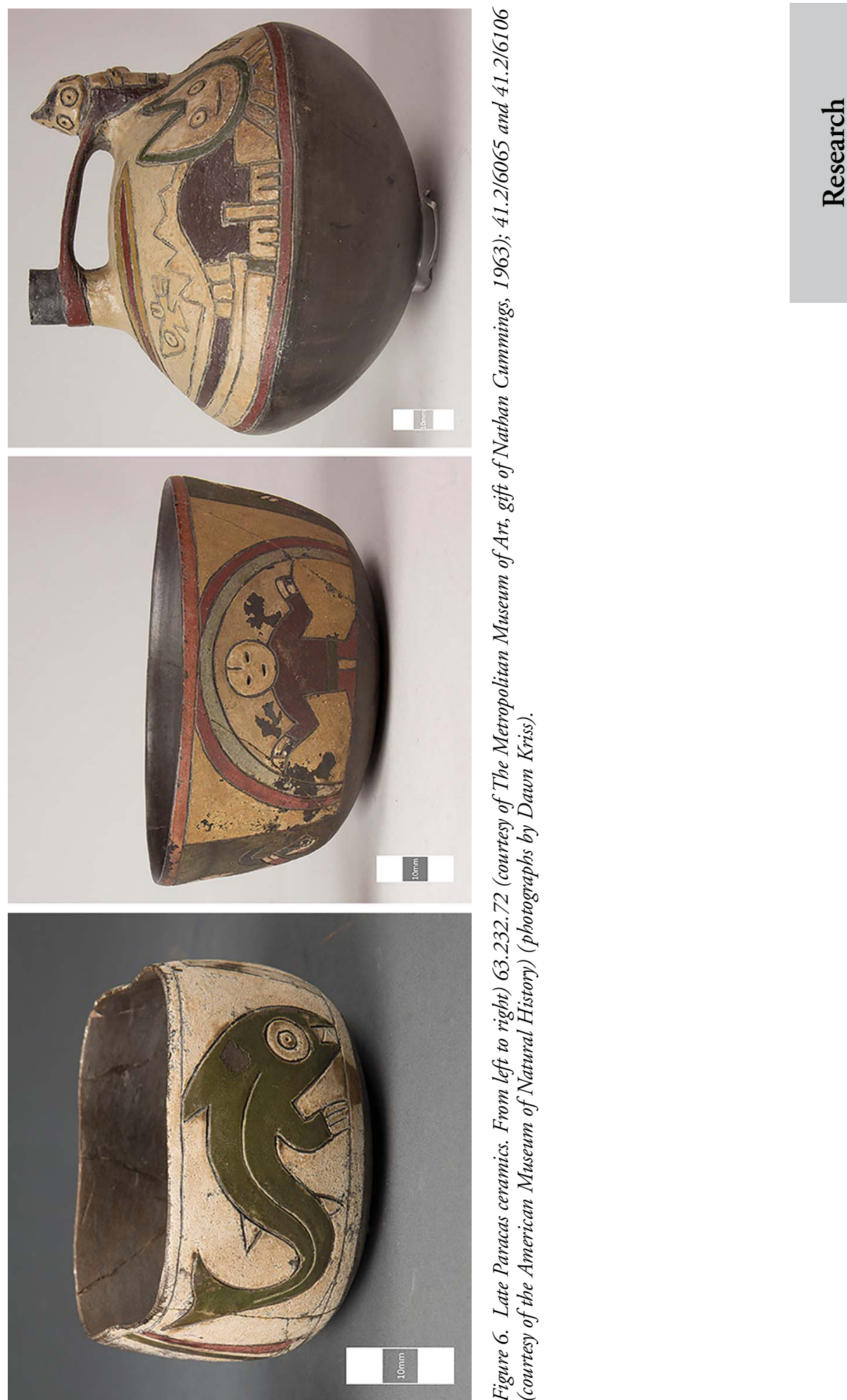

兘

گై

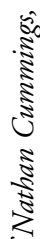
क

$\mathbb{S O}^{-2}$

$\int^{\frac{1}{2}}$

$\frac{3}{3}$

$\sum$

$\frac{\sqrt{2}}{\sqrt[3]{2}}$

8

垔

है

की

डे ने

竞 $\frac{2}{2}$

N 5

ขิ

ते है

₹ิ

.20

8 สี

券莡

इ

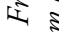

s

辛

ड

3

है

त स

ปี้

6

这弪

(C) Antiquity Publications Ltd, 2018 
developed a 10-phase relative sequence-known as the Ocucaje sequence-for the Ica Valley, from which most of our sample originates. This is anchored by absolute dates from Ica and other south coast valleys (Wallace 1962; Paul 1991; DeLeonardis 2005; Unkel \& Kromer 2009). Additionally, a number of stylistic terms were attributed to the vessels when they first entered the museum collections. Sawyer's (1966: 13 \& 73) relative chronology utilises terms such as "Formative Paracas", for which he believes Chavín cultural influence-from the north-central highlands of Peru - to be the strongest, or "Juan Pablo Style" to refer to a specific ceramic group from the Juan Pablo cemeteries (Sawyer 1966: 103). Soldi (1956) titles the description of his finds as Chavin en Ica, also referencing the influence of the important pilgrimage centre of Chavín de Huantar to the north of the Paracas region (Figure 2). These terms and regional divisions are taken into consideration in our analysis. In this article, we refer broadly to early, middle and late phases that correspond to the established Ocucaje sequence chronology.

The basis of the 10-phase Ocucaje sequence, and other efforts at Paracas chronology, correspond in part to a progression of stylistic attributes. In the early phases (phases 1-4), these attributes centre around 'Chavinoid' vessel forms, such as straight-sided bowls with flat or almost flat bottoms, ridged-lip spouts and feline iconography (Wallace 1962: 312; Menzel et al. 1964: 18-19, 21-22; DeLeonardis 2005: 33-36; Isla 2009: fig. 8.3; Kaulicke et al. 2009: fig. 16; Reindel 2009: fig. 25.4) (Figure 3). Chavinoid imagery in the earlier phases gives way to more highly stylised iconography and abstract designs in the middle and late phases (phases 5-8). The latest phases of the sequence (phases 9-10) demonstrate the introduction of new icons, such as the 'Oculate Being' and a number of new vessel forms. The sequence terminates with the end of post-fire paints and the beginning of the broader use of pre-fired slip paints (Menzel et al. 1964: 251). A key research question addressed here is whether the materials - binders and pigments—used in post-fire painting changed over time in relation to these shifts in vessel form and iconography.

In order to test both for temporal and regional variation in materials, the vessels were selected according to their forms and iconography from both the AMNH collection (Figures $3 \& 6$ ) and the MMA, corresponding to the early, middle and late Paracas phases (Figures 3 $\& 5$ ), with some transitional and early Nasca styles (Figure 6). We demonstrate in this article that the chronological changes in vessel form and iconography do indeed relate to a change in the materials used for post-fire painting.

\section{Overview of past studies}

While Paracas textiles have received much scholarly attention, technological aspects of Paracas pottery have not. With Richard Newman, Emily Kaplan (1999) compared binders and pigments used on Paracas ceramics in the Ica Valley to known reference standards. Fouriertransform infrared spectroscopy (FTIR), gas chromatography-mass spectrometry (GC-MS) and high-performance liquid chromatography (HPLC) determined that the binder in their sample was of plant origin due to the presence of lupenone, a triterpene characteristic of tree bark. Regarding colourants, Kaplan identified pigments of mineral origin—primarily iron oxides with clays and quartz-as well as copper-based greens and blues. Referencing Kaplan's (1999) study, DeLeonardis (2016) has discussed the processes and meanings

(C) Antiquity Publications Ltd, 2018 
embedded in Paracas post-fire-painted ceramics and the range of expertise in ceramic production and the exchange practices involved.

\section{Study methods and results}

Our study focuses on post-fire-painted vessels, with the goal of identifying both the binders and colourants used to create the paints. There are many suggestions in the literature regarding the nature of the binder used in the paint on Paracas pottery. These include exudates from the Peruvian pepper tree (Schinus molle) (Sawyer 1961: 497; Donnan 1992: 20), the nopal cactus (Opuntia spp.), the algarrobo tree (Prosopius juliflora) (Sawyer 1961: 497; Pang 1992: 192), or the acacia bush (Cercidium praecox) (Donnan 1992: 20; Stone-Miller 2002: 50). Some researchers also speculate that the exudate was heated after painting, to eliminate brushstrokes (Donnan 1992: 22; Stone-Miller 2002: 50).

The paint on Paracas ceramics demonstrates varied preservation. The paint on some objects is compact, glossy and relatively intact. On others, the paint appears powdery and poorly preserved (Figures $4 \& 7$ ). Some scholars have proposed that this variation reflects the use of different binders in different regions (Rowe 1956: 141; Sawyer 1961: 274). Sawyer (1966) has also suggested that a series of different binders was used over time, with earlier binders being primarily resin-based, and the later ones largely gum-based and therefore watersoluble and, presumably, more prone to deterioration. This study aims to test these hypotheses.

Following initial surveys of the collections, preliminary examination of material and X-ray fluorescence spectroscopy (XRF) of over 50 pieces, 14 objects from the MMA and AMNH collections were selected for more detailed examination. These were primarily chosen for their stylistic appearance, approximate age and provenance. Five groups were established based on chronology and iconography to test for changes in paint composition over time and region (Table 1). Additional objects from the Smithsonian's National Museum of the American Indian (NMAI) and the Fowler Museum at UCLA, which fit well within the established dating chronology, were examined with XRF to produce initial pigment characterisation. These results are consistent with other findings in the present study.

Groups 1 and 2 correspond to the early phases of the Paracas ceramic sequence. Early phase ceramics are divided into two groups to distinguish the thick-walled vessels bearing Chavinoid iconography (group 1) from other early Paracas vessels (group 2). Group 3 consists of middle phase Paracas pottery, primarily from Ocucaje. Group 4 comprises middle Paracas ceramics from the Juan Pablo cemeteries, while group 5 consists of late Paracas ceramics from the Ica Valley, along with two sherds probably from Cahuachi in the Nazca Drainage. These two sherds fall in the range of Ocucaje 9, or late Paracas in the Ocucaje sequence, and were selected due to the presence of blue colourants - a rarity in Paracas ceramics.

\section{Binding materials}

A selection of exudates from indigenous Andean plants was collected and analysed to provide reference material for comparison with the Paracas post-fire paint binder. These samples were selected on the basis of geographic relevance, suggestions in the literature (e.g. Sawyer 1961:

(C) Antiquity Publications Ltd, 2018 
Dawn Kriss et al.

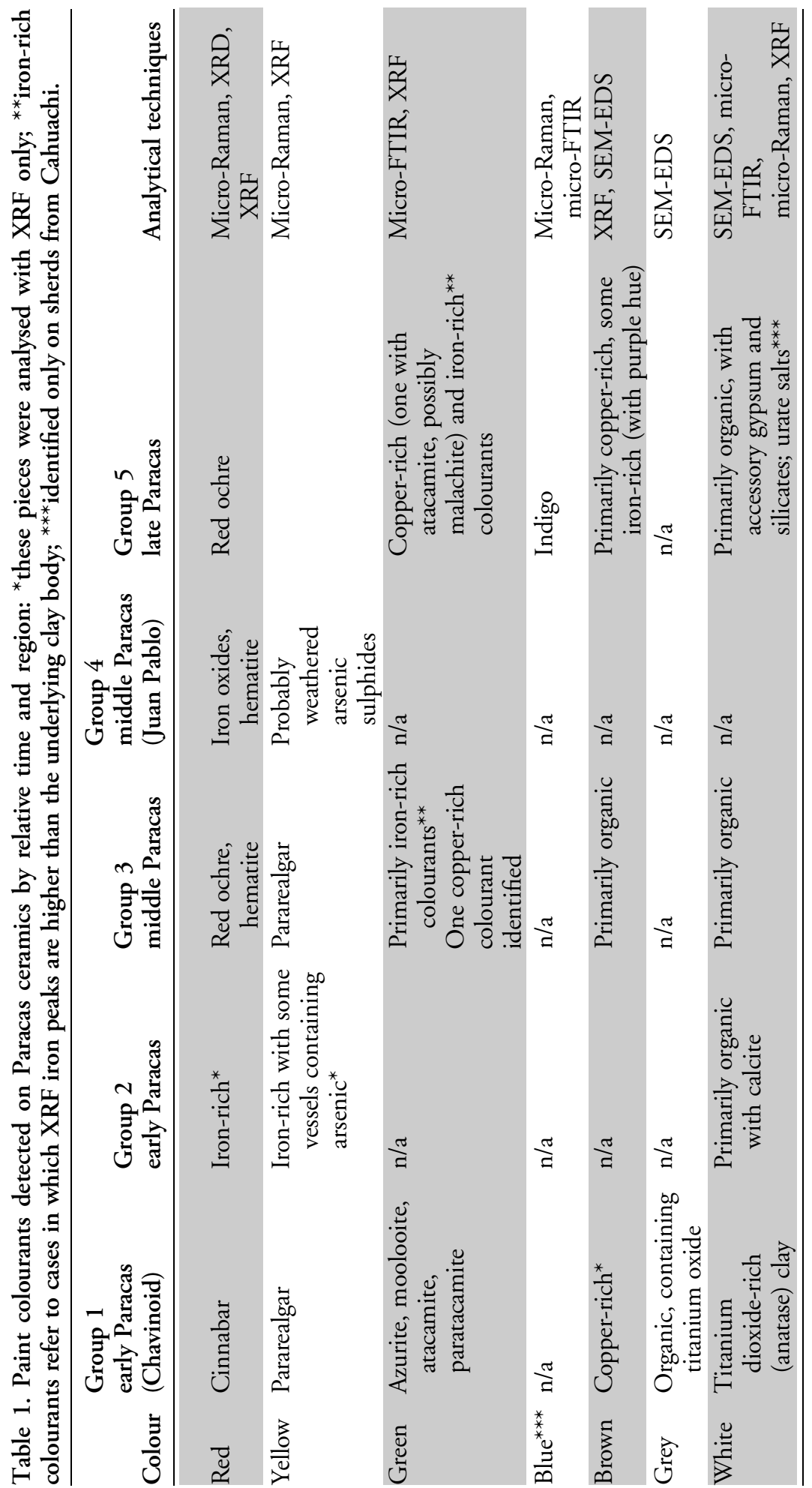

(C) Antiquity Publications Ltd, 2018 


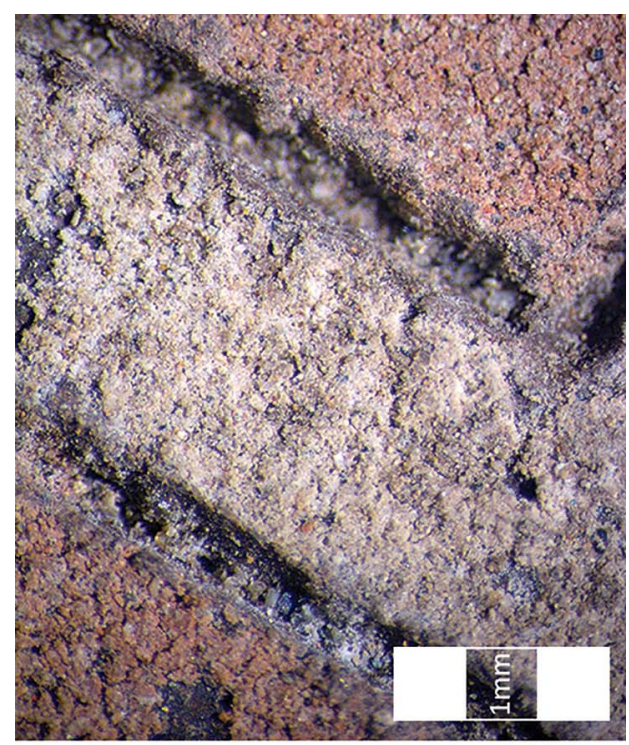

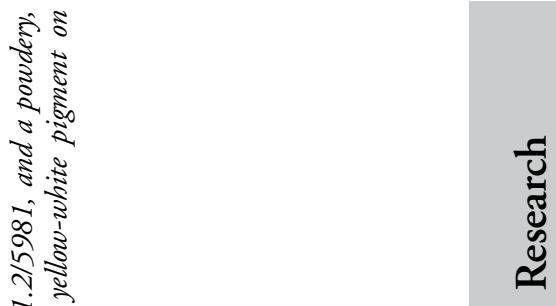

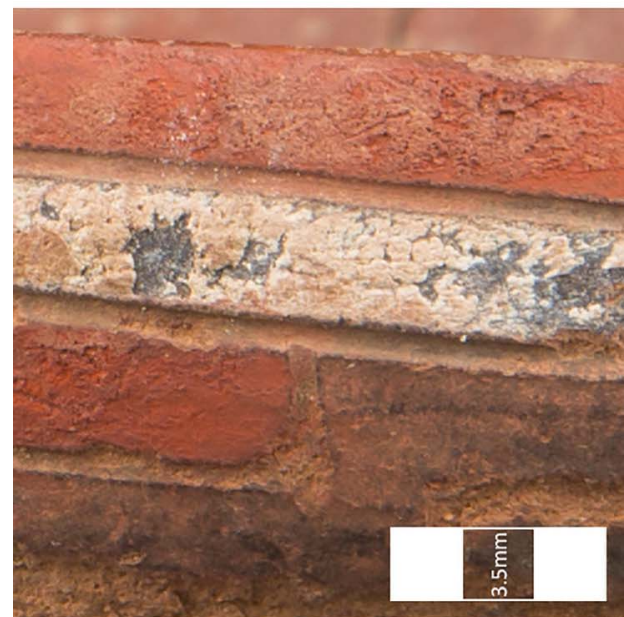

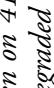

ङ

है है

竎

a.

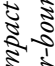

8.

3.

का एक

先

है

हूर

है

运这

ㄴำ

ह

竞 3

这

. 5 ह 8

है है

胥为

sot 4

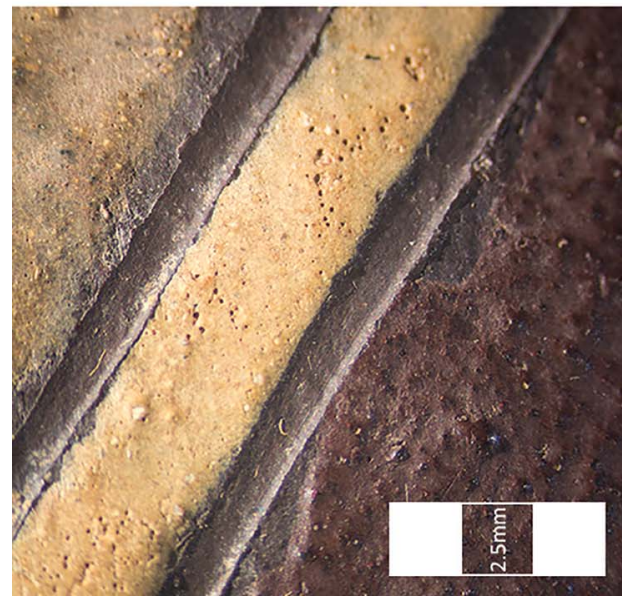

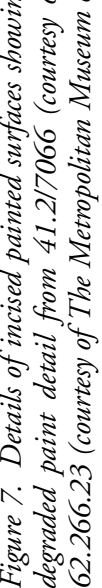

(C) Antiquity Publications Ltd, 2018 
497; Donnan 1992: 20; Stone-Miller 2002: 50), previous analytical studies (e.g. Kaplan 1999), and on preliminary examination at the MMA. The reference samples included Balsam of Peru, Peruvian pepper tree and Algarrobo.

Three representative paint samples were selected from each of the groups described, based on object provenience, estimated date of fabrication and materials identified by previous forms of analysis. Binder analysis was conducted on paint samples using Fourier transform infrared micro-spectroscopy (micro-FTIR), and then a selection of the samples was analysed by thermally assisted hydrolysis and methylation gas chromatography-mass spectrometry (THM-GC/MS) and pyrolysis-GC/MS (py-GC/MS) to characterise further the binding materials by their individual chemical components. In contrast with paint from every other ceramic examined, the binder of the red paint from a Chavinoid vessel in the AMNH collection was shown to contain benzoic- and cinnamic-acid derivatives, as well as the sesquiterpene cadinene that are characteristic of Myroxylon balsamum (Figure 3: right). The presence of other unidentified sesquiterpenes and sesquiterpenoids in this binder may suggest additional plant material used in this formulation.

Analyses of paint samples from other vessels indicate the consistent use of an as yet unidentified plant binder, which is characterised predominantly by triterpenoids, including lupenone, and other components of pentacyclic aliphatic structure. This binder also features a specific fatty acid, possibly derived from a triterpenoid-fatty acid ester, as well as cerotic acid-perhaps from vegetable wax. Gallic acid from a vegetable tannin is also present, which is to be expected from an exudate collected from bark or plant stems containing these phenolic compounds. These acids were made evident on the selected samples treated with a methylating agent (25 per cent tetramethyl ammonium hydroxide in methanol) prior to pyrolysis. In some instances, restoration material—mainly acrylic resin, which would have been applied in modern times-was also detected.

The results indicate a common binding material used for Paracas ceramics over time, with the exception of a formulation made with Myroxylon balsamum, identified on a single vessel corresponding to the early Paracas ceramic sequence (Figure 3: right).

\section{Colourants}

A range of paint colourants was employed in Paracas ceramic production. While up to 15 different colours are seen on some ceramics, the number of colours used on a given piece was typically four to five (Silverman 1991: 359). Red, yellow, green, brown, blue, white and grey paints were selected to analyse the colourants present. Paint samples were initially examined non-invasively with XRF. A subset of colourants were further analysed with microFTIR, Raman micro-spectroscopy (micro-Raman), scanning electron microscopy-energy dispersive spectroscopy (SEM-EDS) and X-ray diffraction (XRD), when appropriate (Table 1).

Classifying colours by visual observation proved difficult in some cases. Some areas that appear 'brown', for instance, on visual inspection in fact contain distinctly coloured pigment particles in sub-surface areas under microscopic examination. This may be due to alteration during burial and possible leaching or erosion of some pigments. The paints identified so far (C) Antiquity Publications Ltd, 2018 
consist primarily of mineral colourants applied in a binder; the exceptions are many of the whites, which seem to be organic in nature, and the use of indigo for blues.

Group 1 differs from all of the other groups in pigment composition (Table 1). Raman and XRF analysis identified the presence of the mercury sulphide cinnabar in the red pigments, and the titanium dioxide anatase (commonly found in white clays) in the white pigments-properties that distinguish these objects from other early, middle and late phase pieces. Further FTIR analyses of group 1 objects detected copper-rich green pigments (atacamite, paratacamite and azurite) and XRF analysis detected copper-rich brown pigments, which are absent in most middle phase pieces. As with the later pieces, however, yellows are characterised by the presence of arsenic, as detected by XRF, and are consistent with the presence of the arsenic sulphide pararealgar, as identified by micro-Raman analysis.

Regional differences in paint composition within the Ica Valley are also apparent. For example, groups 2 and 3-early and middle Paracas ceramics from Ocucaje-use a range of colours, which seem to be primarily iron-based. The high iron content in the ceramic clay bodies supports the hypothesis that iron-rich soils-probably locally sourced-were exploited for producing the ceramic substrates, as well as for the colour in the iron-rich paints. While reds and greens are often iron-rich, yellows show strong arsenic peaks when analysed by XRF, and those paints analysed with micro-Raman and micro-FTIR are primarily composed of pararealgar.

In contrast to the groups 2 and 3 Ocucaje sample, the group 4 Juan Pablo ceramics show more deterioration than those from other sites, with less intact pigment remaining on object surfaces. This is probably due to the site's location near a riverbed (Figure 7: right), which exposed the objects to moisture that may have accelerated their degradation. Pigment use appears to have been more limited in these groups, with reds (iron-based), pinks (with iron and arsenic) and traces of yellows (with high amounts of arsenic) surviving (Table 1). The XRF spectra of white, beige or yellow regions of these Juan Pablo vessels all contain significant quantities of arsenic. SEM-EDS analysis of a white-yellow paint region on one of the vessels indicates an assemblage of quartz and feldspar grains, clay minerals with accessory titanium dioxide and pyrite. Fine-grained particles containing arsenic, iron and oxygen may result from the weathering and oxidation of arsenic sulphide minerals (Lengke $e t$ al. 2009). This possible weathering correlates with the powdery white material observed on all of the Juan Pablo pieces examined, some of which contain traces of yellow pigment under high magnification.

Our results also indicate a shift in style and material choices over time in group 5 (late Paracas) pieces (Table 1). Here, copper-rich pigments are used more frequently, and there is a wider variety of colouration in iron-based pigments, with hues ranging from light brown to a dark, almost purple-brown. Copper-rich pigments refer to those XRF spectra in which the copper peaks are significantly higher than the iron peaks present in the same area. Pieces from the MMA and AMNH collection in group 5 show a substantial increase in the use of copper-rich greens-identified by FTIR and XRD as a mixture of atacamite and malachite. White pigments from the late phase ceramics contain a dominant but unidentified fraction that binds scattered silicate particles and iron oxides and, in one case, gypsum; no particles of titanium oxide were found by either SEM-EDS or Raman analysis, thereby further distinguishing them from samples from earlier periods.

(C) Antiquity Publications Ltd, 2018 
It should be noted that on many pieces where green-pigmented areas were analysed only using XRF, and iron and arsenic identifications were obtained, it was initially supposed that a green-coloured clay or earth was employed. Interpretation of the XRF results requires caution, however, as iron identifications may, in some cases, come from the ceramic body below. It is possible, however, that a blue organic colourant may have been used instead, along with an arsenic sulphide to produce the green colour. This hypothesis warrants further investigation.

Our study suggests both intra- and inter-valley differences in paint composition. Analysis of two sherds with a light blue colourant from Cahuachi in the Nazca Drainage demonstrates completely different pigment composition from others in the study. The two sherds were found in an uncertain area within the large Cahuachi pilgrimage centre. THM-GC/MS analysis of the blue areas on the Cahuachi sherds indicates chemical components associated with urine, including tetramethyluric acid, methylated parabanic acid (methylated oxalylurea) from oxidation of uric acid, as well as methyl hydroxycaffeine. Similarly, areas of white pigment on the sherds also contains large amounts of uric acid. In these paints, SEM-EDS analysis detected spherical white particles of the same chemical composition (their EDS spectra are dominated by nitrogen and potassium, with occasional traces of sodium) as those reported for a white pigment used in African rock art-recognised as originating from snake urine (Mazel et al. 2010). Morphological and compositional similarities with a sample of dried reptile urine (family Chamaeleonidae, species Calumma parsonii), provided to us by AMNH Department of Herpetology, suggest that the white pigment in these ceramics is probably reptile excrement. This organic white, used by itself and mixed with an indigo-based blue colourant, suggests the intentional use of urine-derived pigment, and perhaps an initial use of indigo towards the end of the Paracas ceramic sequence.

\section{Discussion}

The findings in this study highlight a significant number of changes in material use that are suggestive of diachronic and regional variation, and the possible use of certain paints for specific vessel forms. One important exception, however, is that analyses indicate consistent use of an as yet unidentified plant binder in the paint samples—characterised predominantly by triterpenoids-suggesting a common binding material used for the post-fire paint of the Paracas ceramics over time. Our findings also suggest the distinct use of Balsam of Peru in the post-fire paint of an early Paracas bottle (Figure 3: right). The bottle has an unknown provenance, but is thought to be from Coyungo, where early Paracas tombs have been recently discovered (Kaulicke et al. 2009). Thus, the distinct binder could be explained by a number of factors: an early Paracas binding material discontinued in later phases, a regional variation or an imported vessel. Although paint binders on Chavín ceramics have not been analysed, painted ceramics from Chavín sites tend to have less binder and colour diversity — suggesting that this bottle was not painted by 'Chavín' methods. This binder was not detected on other early Paracas ceramics in groups $1 \& 2$ (Table 1), even though this includes a vessel also thought to be from Coyungo (Figure 3: left). It is uncertain, therefore, whether the binder can be attributed to regional variation.

(C) Antiquity Publications Ltd, 2018 
A noticeable difference in paint colourant composition is evident in the early, middle and late phase samples, indicating a shift in the materials used. The three early Paracas vessels bearing Chavinoid iconography from group 1 show a distinct colour palette, with cinnabarbased reds and extensive copper-based pigments (Figure $3 \&$ Table 1). A well-known source of cinnabar is located at Huancavelica, between the northern highlands of the Chavín and the southern region of the Paracas, close to the Paracas Peninsula and Ica Valley. Huancavelica was, therefore, probably the source of cinnabar for both the Chavín (Burger 1992; Burger $\&$ Matos 2002) and the early Paracas paints. As exchange with the Chavín interaction sphere shifted over time (Matsumoto et al. 2013), it seems plausible that different pigment sources were exploited, especially for the colour red. According to our study, the use of cinnabarbased red on ceramics was limited to Chavinoid early Paracas ceramics (e.g. group 1), and was discontinued by the middle Paracas. To identify whether the cinnabar-based red was utilised for specific elements during the early Paracas phases requires further testing.

Additionally, while whites containing titanium dioxide (possibly obtained from clays) were identified in the group 1 paints, whites in groups $2-5$ contained no titanium dioxides or clay minerals (Table 1); only silicates, calcite and gypsum were identified in these pieces. Due to the relatively limited number of samples, these differences in the whites warrant further investigation. This finding also indicates differences in the use of white-coloured paints within groups 1 and 2, or early Paracas ceramics.

During the middle phases of the Paracas tradition (groups 3-4), the use of copper is rare, and more iron-based pigmentation is found. Towards the end of the Paracas sequence-as seen in group 5-the use of copper-rich greens increases sharply, as does the number of colours on the vessels, indicating yet another shift in the use of materials. This increase in the use of pigments containing copper coincides with other shifts in the late Paracas transition (Figure 6), when ceramics are characterised by thinner vessel walls and a change in iconography, with images such as maritime motifs, an "Oculate Being" and figures holding trophy heads (Menzel et al. 1964: 212) being featured.

Two additional findings are significant for the group 5 late Paracas sample. While the use of indigo as a colourant in Paracas textile dyes was previously known (Fester \& Cruellas 1934; Jakes 1991; Wouters \& Rosario-Chirinos 1992), its use in post-fire paints was not. This discovery suggests a shared practice between ceramic and textile colourists, and possibly a regional variant. A second, important result is the identification of the white pigment used on the Cahuachi sherds as dried reptile excrement. How this material was collected and processed, and its correspondence to a temporal or regional practice merits future study.

\section{Conclusions}

This preliminary study has applied multiple analytical techniques to characterise the paint binders and pigments used in post-fire-painted Paracas ceramics. The diachronic changes and regional differences identified in the colourants speak to larger social and economic exchanges reflected in the availability and choice of materials, and to shifts in iconographic styles. These findings represent a cross-section of several museum collections gathered in the early twentieth century. This diverse assemblage of complete vessels has allowed us to 
develop a relative chronology of materials usage. Future comparison of these findings with scientifically excavated and documented material will be the key to validating and expanding our understanding of these trends.

While absolute dating of the pieces was beyond the scope of the present research, obtaining precise dates for objects with known provenance would further refine the interpretation of our results. Changes in the pigments and binders correlate with stylistic and other technological changes, indicating that relative approximations for dates corresponding to the Ocucaje sequence are applicable here. This has been observed in other recent studies as well (DeLeonardis 2005; Dulanto 2013).

Equally important is the fact that the post-fire paint binder has been found to be identical on nearly all of the ceramics analysed-across Ica Valley regions and, especially, through time. The next step will be to expand our reference set of relevant plant exudates. This will allow for further identification of the paint-binding materials, and may suggest how these exudates were collected, processed and applied. Our study has ruled out the use of a number of plant materials that had been previously proposed in the literature, but further field research is necessary to identify elusive materials.

Variations observed in the preservation of the painted surfaces of Paracas vessels were originally suspected to be due to the use of different binders. Instead, our findings indicate that these differences in preservation probably result from a number of factors, including differences in the burial environment, interaction between the binder and colourant and, possibly, methods of paint application. The variation in paint preservation further illustrates the importance of examining pieces from secure archaeological contexts, in order to help clarify whether differences are attributable to chronological sequencing or regional variations.

\section{Acknowledgements}

The AMNH Anthropology Research Program and the Sherman Fairchild Center for Objects Conservation and their Andrew W. Mellon Fellowship funded this research. Special thanks are due to Emily Kaplan at the Smithsonian National Museum of the American Indian collections and to Ben Nigra of the Chincha project. We are also grateful to: Susana Arce and Ruben Garcia Soto at the Museo Regional de Ica; Ulla Holmquist at Museo Larco; Rosa Martinez and Alejandro Soto Velarde at the MNAAHP; Johny Isla of the Palpa project; Jalh Dulanto and Patricia Elena Gonzales Gil at PUCP; Chris De Brer at the Fowler Museum; David Scott at The UCLA/Getty Master's Program; the Brooklyn Museum; Colleen Snyder at the Cleveland Museum of Art; and to Mark Nesbitt at the Kew Economic Botany Collection of the Royal Botanic Gardens at Kew, UK.

\section{References}

BURGER, R.L. 1992. Chavin and the origins of Andean civilization. London: Thames \& Hudson.

Burger, R.L. \& R. Matos. 2002. Atalla: a center on the periphery of the Chavín Horizon. Latin American Antiquity 13: 153-77. https://doi.org/10.2307/971912

Costin, C.L. 2016. Introduction: making value, making meaning: Techné in the pre-Columbian world, in C.L. Costin (ed.) Making value, making meaning: Techné in the
pre-Columbian world: 1-30. Washington, D.C.: Dumbarton Oaks Research Library and Collection.

DeLeonardis, L. 2005. Paracas cultural contexts: new evidence from the west bank of Callango. Andean Past 7: 27-55.

- 2016. Encoded process, embodied meaning in Paracas post-fired painted ceramics, in C.L. Costin (ed.) Making value, making meaning: Techné in the pre-Columbian world: 129-66. Washington, D.C.: Dumbarton Oaks Research Library and Collection. 
Dobres, M.-A. 2000. Technology and social agency: outlining a practice framework for archaeology. Malden (MA): Blackwell.

Donnan, C.B. 1992. Ceramics of ancient Peru. Los Angeles (CA): Fowler Museum of Cultural History.

Dulanto, J. 2013. Puerto Nuevo: redes de intercambio a larga distancia durante la primera mitad del primer milenio antes de nuestra era. Boletin de Arqueología PUCP 17: 103-32.

Fester, G.A. \& J. Cruellas. 1934. Colorantes de Paracas. Revista Museo Nacional III: 154-63.

IsLA, J. 2009. From hunters to regional lords: funerary practices in Palpa, Peru, in M. Reindel \& G.A. Wagner (ed.) New technologies for archaeology: multidisciplinary investigations in Palpa and Nasca, Peru: 119-39. Berlin: Springer.

JaKes, K. 1991. Physical and chemical analysis of Paracas fibers, in A. Paul (ed.) Paracas art and architecture: object and context in south coastal Peru: 222-39. Iowa City: University of Iowa Press.

Kaplan, E. 1999. Technical studies of post-fire paint on Paracas ceramics. Paper presented at the $64^{\text {th }}$ Annual Meeting of the Society for American Archaeology, Chicago, March 23-28, 1999.

Kaulicke, P., L. Fehren-Schmitz, M. Kolp-Godoy, P. Landa, O. Loyola, M. Palma, E. Tomasto, C. Vergel \& B. Vogt. 2009. Implicancias de un área funeraria de periodo formative tardío en el departamento de Ica. Boletin de Arqueologia PUCP 13: 289-322.

Lapiner, A. 1976. Pre-Columbian art of South America. New York: Harry N. Abrams.

LengKe, M.F., C. SANPAWANitchakit \& R.N. Tempel. 2009. The oxidation and dissolution of arsenic-bearing sulfides. The Canadian Mineralogist 47: 593-613. https://doi.org/10.3749/canmin.47.3.593

Matsumoto, Y., R. Gutierrez \& Y. Cavero. 2013. Domestic occupations in the Late Initial Period and Early Horizon: new evidence from Campanayuq Rumi, Peru. Andean Past 11: 169-213.

Mazel, V., P. Richardin, D. Touboul, A. Brunelle, C. Richard, E. Laval, P. Walter \& O. LAprÉVote. 2010. Animal urine as painting materials in African rock art revealed by cluster ToF-SIMS mass spectrometry imaging. Journal of Mass Spectrometry 45: 944-50. https://doi.org/10.1002/jms.1789

Menzel, D., J.H. Rowe \& L.E. Dawson. 1964. The Paracas pottery of Ica: a study in style and time
(Volume 50: University of California

Publications in American Archaeology and Ethnology). Berkeley: University of California Press.

PANG, H.D. 1992. Pre-Columbian art: investigations and insights. Norman: University of Oklahoma Press.

Paul, A. 1991. Paracas: an ancient cultural tradition on the south coast of Peru, in A. Paul (ed.) Paracas art and architecture: object and context in south coastal Peru: 1-33. Iowa City: University of Iowa Press.

Reindel, M. 2009. Life at the edge of the desert: archaeological reconstruction of the settlement history in the valleys of Palpa, Peru, in M. Reindel \& G.A. Wagner (ed.) New technologies for archaeology: multidisciplinary investigations in Palpa and Nasca, Peru: 439-61. Berlin: Springer. https://doi.org/10.1007/978-3-540-87438-6_25

Rowe, J.H. 1956. Archaeological explorations in southern Peru: 1954-1955. American Antiquity 22: 135-51. https://doi.org/10.2307/276816

SAWYER, A.R. 1961. Paracas and Nazca iconography, in S.K. Lothrop (ed.) Essays in pre-Columbian art and archaeology: 269-98 \& 497. Cambridge (MA): Harvard University Press. https://doi.org/10.4159/harvard. 9780674864917.c22

- 1966. Ancient Peruvian ceramics: the Nathan Cummings Collection. New York: The Metropolitan Museum of Art.

ShimadA, I. (ed.). 1994. Tecnología y organización de la producción cerámica prehispánica en los Andes. Lima: PUCP Fondo Editorial.

Silverman, H. 1991. The Paracas problem: archaeological perspectives, in A. Paul (ed.) Paracas art and architecture: object and context in south coastal Peru: 349-416. Iowa City: University of Iowa Press.

Soldi, P. 1956. Chavin en Ica. Ica: Imprenta Voz de Ica.

Stone-Miller, R. 2002. Art of the Andes: from Chavin to Inca. New York: Thames \& Hudson.

Tello, J. \& T. Mejía. 1979. Paracas segunda parte: Cavernas y Necrópolis. Lima: Universidad Nacional San Marcos.

UnKel, I. \& B. Kromer. 2009. The clock in the corn cob: on the development of a chronology of the Paracas and Nasca period based on radiocarbon dating, in M. Reindel \& G.A. Wagner (ed.) New technologies for 
archaeology: multidisciplinary investigations in Palpa and Nasca, Peru: 231-44. Berlin: Springer. https://doi.org/10.1007/978-3-540-87438-6_14

Wallace, D.T. 1962. Cerrillos, an early Paracas site in Ica, Peru. American Antiquity 27: 303-14. https://doi.org/10.2307/277797
Wouters, J. \& N. Rosario-Chirinos. 1992. Dye analysis of pre-Columbian Peruvian textiles with high-performance liquid chromatography and diode-array detection. Journal of the American Institute for Conservation 31: 237-55. https://doi.org/10.2307/3179495

Received: 2 February 2018; Revised: 31 May 2018; Accepted: 5 June 2018

(C) Antiquity Publications Ltd, 2018 